\title{
Influence of sex and disease on illness-related concerns in inflammatory bowel disease
}

\author{
R Maunder MD ${ }^{1}$, B Toner PhD $^{2}$, E de Rooy PhD ${ }^{3}$, D Moskovitz $^{4}$
}

\begin{abstract}
R Maunder, B Toner, E de Rooy, D Moskovitz. Influence of sex and disease on illness-related concerns in inflammatory bowel disease. Can J Gastroenterol 1999;13(9):728-732.
\end{abstract}

Identifying the normal concerns of people with ulcerative colitis and Crohn's disease (CD) facilitates a comprehensive approach to their medical care. Clinically, it can be easily appreciated that the concerns of men and women with inflammatory bowel disease (IBD) may differ and that this may have a substantial impact on both coping and treatment decisions. However, sex differences have received little empirical study.

METHODS: Significant differences between the sexes on the 25 items of the Rating Form of IBD Patient Concerns (RFIPC) were determined in 343 subjects by univariate ANOVA with disease type and sex as factors, correcting for multiple comparisons and covarying for IBD symptom severity.

RESULTS: Compared with men, women reported higher levels of IBD symptom severity and higher overall RFIPC scores. Women were more concerned than men about feelings related to their bodies, attractiveness, feeling alone and having children. There was an interaction between disease and sex regarding concern about sexual performance and intimacy. In both cases, men with $\mathrm{CD}$ reported less concern than each other comparison group. The illness concerns that differ between sexes are not the most intense concerns in either sex.

DISCUSSION: These results confirm that sex has a significant influence on a number of illness concerns, particularly concerns related to self-image and relationships. The interaction of disease type and sex with respect to concern over sexual performance and intimacy is open to several potential explanations and requires further research. Sex differences should be considered in the treat- ment of IBD. Specific inquiry into sex-specific concerns may be useful for the clinician. Further research is required to replicate these retrospective findings.

Key Words: Crohn's disease; Inflammatory bowel disease; Ulcerative colitis

\section{Influence du sexe et de la maladie sur les soucis liés à la santé dans la MII}

OBJECTIF : Identifier les soucis qui préoccupent en général les gens atteints de colite ulcéreuse et de maladie de Crohn (MC) permettrait d'établir une approche globale face au traitement médical. Sur le plan clinique, on peut facilement constater que les hommes et les femmes atteints de maladies inflammatoires de l'intestin (MII) ne se préoccupent pas des mêmes choses et que cela peut exercer un impact substantiel tant sur le processus d'adaptation que sur les décisions thérapeutiques. Par contre, les différences liées au se xe ont peu étéétudiées de façon empirique. MÉTHODES : Des différences significatives entre les sexes ont été notées quant aux réponses fournies par 343 sujets à 25 questions du Rating Form of IBD Patient Concerns (RFIPC); c'est ce qui ressort d'une analyse univariée de la variance avec, comme facteurs, le type de maladie et le sexe, une correction ayant été apportée pour tenir compte de comparaisons multiples et pour la covariante se rattachant à la gravité des symptômes de MII.

RÉSULTATS : Comparativement aux hommes, les femmes ont fait état de symptômes de MII plus marqués et de scores en général plus hauts au RFIPC. Les femmes s'en font davantage au sujet de leur corps, de leur apparence, de la solitude et des enfants. On a noté une interaction entre maladie et sexe en ce qui a trait aux inquiétudes liées à la performance

voir page suivante

${ }^{1}$ Department of Psychiatry, University of Toronto, and Department of Psychiatry, Mount Sinai Hospital; ${ }^{2}$ Department of Psychiatry, University of Toronto, and Women's Health Program, Clarke Institute of Psychiatry, Toronto, Ontario; ${ }^{3}$ Department of Psychology, Wayne State University, Detroit, Michigan, USA; ${ }^{4}$ Faculty of Medicine, University of Toronto, Toronto, Ontario

Correspondence and reprints: Dr RG Maunder, Department of Psychiatry, 9th Floor, Mount Sinai Hospital, 600 University Avenue, Toronto, Ontario M5G 1X5. Telephone 416-586-3200, fax 416-586-8654, e-mail RMaunder@mtsinai.on.ca

Received for publication June 2, 1998. Accepted November 10, 1998 
sexuelle et à l'intimité. Dans les deux cas, les hommes atteints de maladie de Crohn se sont révélés moins préoccupés que les autres groupes comparés. Pour les deux sexes, et bien qu'elles semblent différer d'un sexe à l'autre, les préoccupations engendrées par la maladie ne sont pas celles qui comptent le plus.

DISCUSSION : Ces résultats confirment que le sexe influe significativement sur un certain nombre de préoccupations engendrées par la maladie, particulièrement en ce qui a trait à l'image de soi et aux rapports interpersonnels. Le lien entre le type de maladie et le sexe pour ce qui est des préoccupations relatives aux performances sexuelles et à l'intimité peut s'expliquer de plusieurs façons et nécessite une recherche plus approfondie. Les différences liées au sexe doivent entrer en ligne de compte lors du traitement de la MII. Selon le sexe de ses patients, le médecin peut trouver utile de les interroger sur leurs préoccupations précises. Il faudra approfondir la recherche pour tenter de reproduire ces conclusions rétrospectives.
$I^{\mathrm{d}}$ dentifying the normal concerns of people with ulcerative colitis (UC) and Crohn's disease (CD) facilities a comprehensive approach to medical care. The identification of specific concerns that are more prevalent in particular populations is important clinically because it allows the clinician and patient to collaborate fully in treatment choices among, for example, different surgical interventions that have similar clinical outcomes but distinct impact on quality of life (1). Identifying population-specific patterns of concern may also facilitate the development of psychosocial interventions for people with greater distress.

Research on disease-specific quality of life in inflammatory bowel disease (IBD) has been advanced by the development of two types of self-report instruments. The first type provides a quantitative measure of global health-related quality of life that is sensitive enough to detect small differences among groups and changes over time. This is ideal for use in clinical trials. The most widely used and psychometrically robust of these instruments is the Inflammatory Bowel Disease Questionnaire (IBDQ) (2). The second type of instrument quantifies the degree of concern with specific issues related to IBD. This type of instrument is ideal for descriptive study of distinct IBD populations and is exemplified by the Rating Form of IBD Patient Concerns (RFIPC) (3). The RFIPC is widely used and has allowed descriptive distinctions to be made between the concerns of UC patients and those of CD patients in community samples (4), among culturally distinct populations (5) and between general outpatients and patients seeking psychological counselling (6).

Clinically, it can be easily appreciated that the concerns of men and women with IBD may differ and that these differences may have a substantial impact on coping strategies and treatment decisions. For example, there are sex-specific differences in the potential adverse effects of corticosteroids (osteoporosis) and pelvic pouch surgery (dyspareunia, impotence). More generally, both illness and treatment may have dramatic effects on body image, appearance, occupational function and attitudes toward sexuality that may be perceived differently by women and men. Finally, there is growing evidence that there is a high prevalence of a history of physical or sexual abuse in female gastroenterological patients (7), including a prevalence as high as $42 \%$ in IBD (8). This may affect disease-related concerns, such as concerns about feeling out of control, body image, sexuality and the availability of support.

The description of differences in IBD-related concerns between women and men has received little empirical study. We provide evidence for differences between men and women in self-reported disease concerns in IBD.

\section{SUBJECTS AND METHODS}

Subjects who had completed the RFIPC and a survey of demographic and disease-related variables in one of three previous studies were combined for this comparison. In each study, diagnosis was confirmed by endoscopy or surgical pathology. Each study involved patients from the same tertiary care IBD specialty centre. Study 1 has been previously described (6) and included 276 subjects (140 UC and 136 CD; $59 \%$ female) of which 43 patients were referred for psychiatric assessment. Study 1 subjects completed the study questionnaires in the gastroenterologist's office (in 1994 and 1995) or after their first visit to the psychiatrist (in 1995 and 1996). Study 2 comprised 40 subjects (39 UC and one CD; $68 \%$ female) recruited from a gastroenterologist's office between January 1997 and April 1998, unselected except for a prior record of antineutrophil cytoplasmic antibody titre. Study 2 subjects were contacted by telephone and completed the questionnaire through the mail. Instruments not reported here that were completed by study 2 subjects included a coping questionnaire, a social support questionnaire and the IBDQ. Study 3 resulted from a survey of every patient receiving surgery for IBD in a 13 -month period from September 1996 to September 1997. Study 3 contributed 78 subjects (41 UC and 37 CD; 51\% female). Numerous instruments that are not reported here were completed by study 3 subjects, including measures of relationship security, psychiatric symptoms, alexithymia, coping strategies and the IBDQ.

To eliminate subjects who may have participated in more than one study, subjects from different studies who were potentially identical based on sex, diagnosis, education and age were identified. From these groups of potentially identical subjects, one subject was selected at random by a coin toss and the others were removed from the sample. By this process, 51 subjects were removed, leaving 343 subjects (186 UC and 157 CD; 57\% female) for data analysis.

The RFIPC is a widely used 25-item self-administered questionnaire that probes specific domains of concern to IBD patients. Higher scores for each item (0 to 100) indicate a greater degree of concern. Each item is introduced with the phrase "Because of your condition, how concerned are you with...". The RFIPC has adequate psychometric properties $(3,4)$. 
TABLE 1

Differences in demographic and illness-related variables between women and men

\begin{tabular}{lccc}
\hline & $\begin{array}{c}\text { Female } \\
(\mathbf{n = 1 9 4 )}\end{array}$ & $\begin{array}{c}\text { Male } \\
(\mathbf{n}=149)\end{array}$ & $\mathbf{P}$ \\
\hline Age (mean years) & 36.1 & 37.5 & $\mathrm{~ns}$ \\
Education (mean years) & 14.0 & 14.2 & $\mathrm{~ns}$ \\
Diagnosis (\% ulcerative colitis) & 52.1 & 57.0 & $\mathrm{~ns}$ \\
Severity of IBD-related symptoms & 10.7 & 9.1 & 0.04 \\
Total concern (RFIPC) & 46.0 & 36.7 & $\leq 0.001$ \\
\hline
\end{tabular}

$\chi^{2}$ for discrete variables and t tests for continuous variables. IBD Inflammatory bowel disease; ns Not significant; RFIPC Rating Form of IBD Patient Concerns

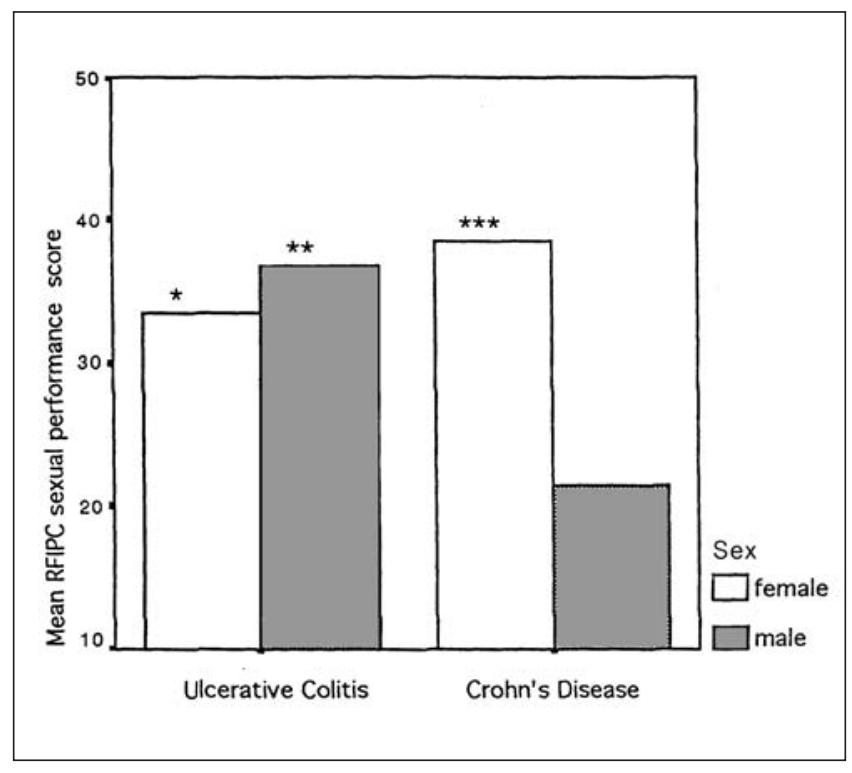

Figure 1) concern about sexual performance in inflammatory bowel disease (IBD) by sex and disease. RFIPC Rating Form of IBD Patient Concerns. $* P<0.05, * * P<0.01, * * * P<0.001$ versus men with Crohn's disease by t test

In the absence of data required for valid measurement of disease activity, perceived symptom severity was measured by self-report of 13 symptoms related to IBD (abdominal pain, diarrhea, bleeding, fever, nausea and/or vomiting, joint pain and/or swelling, skin disease, eye disease, loss of bowel control, difficulty with gas, frequent trips to the bathroom, dependence on medication for diarrhea and dependence on medication for pain) each graded on a four-point scale and then summed.

Given the post-hoc assembly of the study sample, data analysis was designed conservatively. For descriptive purposes, comparisons of total RFIPC scores and demographic variables among data sources, between diseases and between sexes were tested with $t$ tests for independent samples. Univariate ANOVA was employed to determine the contribution of sex, disease, and data source and their two-way and three-way interactions to individual RFIPC items, covarying for symptom severity (which was found to differ between
TABLE 2

Inflammatory bowel disease concerns that differ by sex, disease or their interaction

\begin{tabular}{lcccccc}
\hline & \multicolumn{2}{c}{ Disease } & \multicolumn{2}{c}{ Sex } & \multicolumn{2}{c}{ Sex $\times$ disease } \\
& F & P & F & P & F & P \\
\hline Having children & 2.33 & $\mathrm{~ns}$ & 20.68 & $<0.001$ & 3.71 & $\mathrm{~ns}$ \\
Attractiveness & 3.19 & $\mathrm{~ns}$ & 18.03 & $<0.001$ & 2.65 & $\mathrm{~ns}$ \\
Feelings about body & 3.94 & $\mathrm{~ns}$ & 13.02 & $<0.001$ & 2.92 & $\mathrm{~ns}$ \\
Feeling alone & 3.54 & $\mathrm{~ns}$ & 12.47 & $<0.001$ & 2.10 & $\mathrm{~ns}$ \\
Intimacy & 2.60 & $\mathrm{~ns}$ & 4.32 & $\mathrm{~ns}$ & 13.45 & $<0.001$ \\
Sexual performance & 1.20 & $\mathrm{~ns}$ & 1.22 & $\mathrm{~ns}$ & 9.70 & 0.002 \\
\hline
\end{tabular}

Results of univariate ANOVA for each concern of the Rating form for IBD Patient Concerns, covarying for IBD symptom severity. Using the Bonferronicorrection for comparison of 25 items, differences are reported if they have a significance of at least 0.002. ns Not significant

sexes). The Bonferroni test was used to correct for chance findings due to multiple comparisons. Only between-group differences with two-tailed significance less than or equal to 0.002 were considered significant. Finally, the intensities of RFIPC concern items for each sex were ranked to provide context for the discussion of concerns that differed between sexes. Statistical analyses were performed with SPSS software (SPSS Inc, Chicago, Illinois).

\section{RESULTS}

There was no difference in mean RFIPC score among subjects from the study 1 mixed tertiary care sample (mean $\pm \mathrm{SD}$, $42.59 \pm 22.50$ ), the study 2 outpatient gastroenterology sample $(39.06 \pm 21.15)$ and the study 3 surgical sample (41.14 \pm 23.67$)$. The mean RFIPC did not differ between UC $(42.04 \pm 23.97)$ and CD $(41.81 \pm 20.88)$ patients.

Women and men did not differ significantly in age, education or in the proportion of the sample with UC or CD. Women were significantly more likely than men to endorse higher levels of IBD symptom severity and higher overall RFIPC scores (Table 1).

There was no main effect of data source on any RFIPC item and no interaction between data source and sex or disease found in the univariate ANOVAs. Therefore, ANOVA results are reported only for sex and disease (Table 2). Four IBD concerns differed significantly between sexes. In each case the difference was due to greater concern of women than of men. These concerns were feelings about one's body (women 52.13 \pm 34.8 , men $38.16 \pm 33.83$ ), attractiveness (women $46.41 \pm 33.29$, men $28.20 \pm 31.24$ ), feeling alone (women $37.42 \pm 32.34$, men $23.91 \pm 30.39$ ) and having children (women $35.53 \pm 37.23$, men 17.11 \pm 26.84 ).

Two IBD concerns were found to be affected by an interaction between disease and sex. These were intimacy and sexual performance (Table 2). In both cases (Figures 1,2), this interaction was due to a difference between sexes in CD patients that was not present in UC patients. When values for each sex were compared between diseases, the differences in $\mathrm{CD}$ were due to lower reporting of concern over sexual performance and intimacy in CD men (versus each of UC 


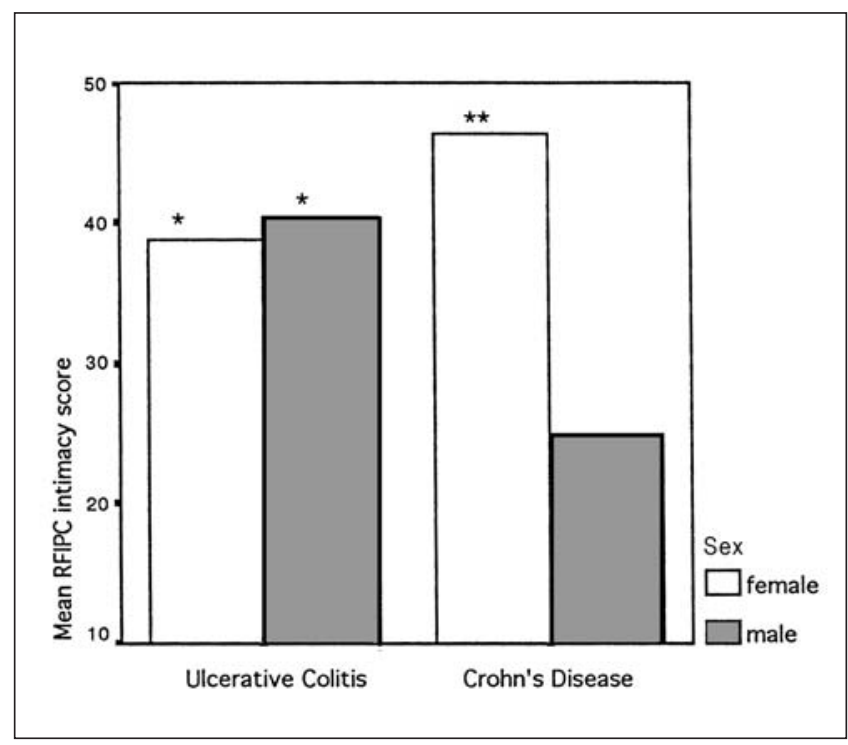

Figure 2) Concern about intimacy in inflammatory bowel disease (IBD) by sex and disease. RFIPC Rating Form of IBD Patient Concerns. $* P<0.01, * * P<0.001$ compared with men with Crohn's disease by test

men, $\mathrm{UC}$ women and $\mathrm{CD}$ women) rather than a greater reporting of concern in $\mathrm{CD}$ women.

The ranked intensity of concerns in men and women are presented in Table 3.

\section{DISCUSSION}

These results suggest that there is a significant effect of sex on the intensity of four illness-related concerns. After correcting for changes in concerns due to perceived symptom severity, women with IBD reported greater concern over feelings about their bodies, their attractiveness, feeling alone and having children. It is noteworthy that the concerns that distinguish men and women are not the most intense concerns of either sex. In our sample the top three concerns of both men and women were energy level, medication effects and the uncertainty of the disease, a ranking that is consistent with previous reports of concerns in IBD (9). Only one of the four concerns that were more prominent in women feelings about one's body - was in the top 10 concerns of women of the 25 RFIPC items.

If the main benefit of studying between-group differences in illness concerns is to direct clinicians toward the areas that most require attention and inquiry, then we conclude that the clinician's focus should be twofold. First, attention must be paid to the concerns that are generally intense in all people with IBD, especially energy level, medication effects and uncertainty (a clinical approach to illness uncertainty has been described elsewhere [10]). Second, special attention to sex-related concerns is warranted in women with IBD. We speculate that this may be of particular importance for male clinicians dealing with female patients because in this situation a patient may be reluctant to introduce sexspecific concerns without specific inquiry. These results confirm that the self-image and relationship issues that are often thought to be of greater concern to women than men in
TABLE 3

Ranking of intensity of inflammatory bowel disease-related concerns by sex

\begin{tabular}{lcc}
\hline & Rank in women & Rank in men \\
\hline Energy level & 1 & 1 \\
Medication effects & 2 & 2 \\
Uncertain nature of disease & 3 & 3 \\
Having surgery & 4 & 8 \\
Having an ostomy bag & 5 & 4 \\
Reaching full potential & 6 & 5 \\
Being a burden & 7 & 7 \\
Feelings about body* & 8 & 12 \\
Losing bowel control & 9 & 6 \\
Pain and suffering & 10 & 9 \\
Feeling out of control & 11 & 17 \\
Unpleasant odors & 12 & 11 \\
Attractiveness* & 13 & 20 \\
Obtaining quality medical care & 14 & 13 \\
Financial difficulties & 15 & 15 \\
Intimacy* & 16 & 16 \\
Getting cancer & 17 & 10 \\
Feeling alone* & 18 & 21 \\
Sexual drive & 19 & 14 \\
Dying early & 20 & 18 \\
Sexual performance* & 21 & 19 \\
Having children* & 22 & 25 \\
Feeling dirty or smelly & 23 & 23 \\
Passing disease on & 24 & 25 \\
Being treated as different & 25 & \\
\hline
\end{tabular}

*Items with significant sex differences or sex $\times$ disease interactions (Table 2)

Western cultures (attractiveness, concern with body, feeling alone and having children) are relevant to the experience of living with IBD.

The results of this study also indicate an interaction of disease and sex relating to concern over sexual performance and intimacy. In particular, men with CD report lower levels of each of these concerns than any other grouping. This may be due to a lower degree of concern about these aspects of disease in this group, or to a reluctance to report the higher degree of concern that appears to be normative in this sample. A reluctance to report concern over sexual performance in men is consistent with common notions of male attitudes toward threatened sexual potency, but does not account for this trend being more pronounced in CD than in UC. An alternative explanation is that, because $\mathrm{CD}$, especially in a tertiary care centre, tends to be associated with a more relentless disease course, greater dependence on medication and noncurative surgery, the men in our sample with $C D$ were more likely than the men with UC to have adopted a 'given up' attitude toward sexual performance and thus to report less concern. Further study is required to better understand this interaction.

The findings presented here serve to validate a clinical intuition that sex differences contribute significantly to the 
experience of disease and treatment and need to be accounted for in the clinician-patient partnership. Because some specific treatment choices in IBD differentially affect qualitative outcomes (1), future research is required to determine whether it is beneficial to match treatments to patient

\section{REFERENCES}

1. Maunder RG, Cohen Z, McLeod RS, Greenberg GR. Effect of intervention in inflammatory bowel disease on health-related quality of life: a critical review. Dis Colon Rectum 1995;38:1147-61.

2. Guvatt G, Mitchell A, Irvine EJ, et al. A new measure of health status for clinical trials in inflammatory bowel disease. Gastroenterology $1989 ; 96: 804 \cdot 10$.

3. Drossman DA, Leserman J, Li ZM, Mitchell CM, Zagami EA, Patrick DL. The rating form of IBD patient concerns: a new measure of health status. Psychosom Med 1991;53:701-12

4. Drossman DA, Patrick DL, Mitchell CM, Zagami EA, Appelbaum MI. Health-related quality of life in inflammatory bowel diseases: Functional status and patient worries and concerns. Dig Dis Sci $1989: 34: 1379-86$.

5. Levenstein S, Li Z, Drossman DA. Cross-cultural variation in disease-related concerns among patients with inflammatory bowel disease. Gastroenterology 1998;114:1021. (Abst) characteristics, including sex. The limitations imposed by the methodology of the current comparison also suggest that further research is required, specifically designed to investigate the associations between sex and the subjective experience of disease.

6. Maunder RG, de Rooy EC, Toner BB, et al. Health-related concerns of people who receive psychological support for inflammatory bowel disease. Can J Gastroenterol 1997;11:681-5.

7. Drossman DA, Leserman J, Nachman G, et al. Sexual and physical abuse in women with functional or organic gastrointestinal disorders. Ann Intern Med 1990;113:828-33.

8. Walker EA, Gelfand AN, Gelfand MD, Katon WJ. Psychiatric diagnoses, sexual and physical victimization, and disability in patients with irritable bowel syndrome or inflammatory bowel disease. Psychol Med 1995;25:1259-67.

9. Drossman DA, Leserman J, Mitchell CM, Li ZM, Zagami EA, Patrick DL. Health status and health care use in persons with inflammatory bowel disease: A national sample. Dig Dis Sci 1991;36:1746-55.

10. Maunder R, Esplen MJ. Facilitating adjustment to inflammatory bowel disease: a model of psychosocial intervention in non-psychiatric patients. Psychother Psychosom 1999;68:230-40. 


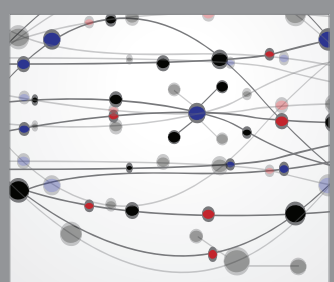

The Scientific World Journal
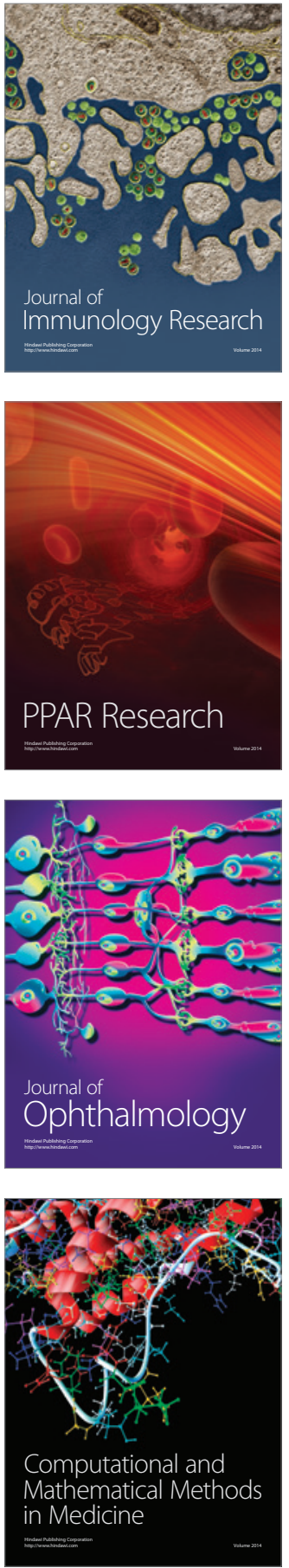

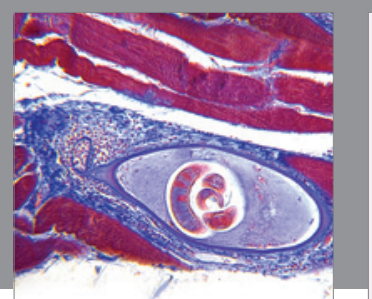

Gastroenterology Research and Practice

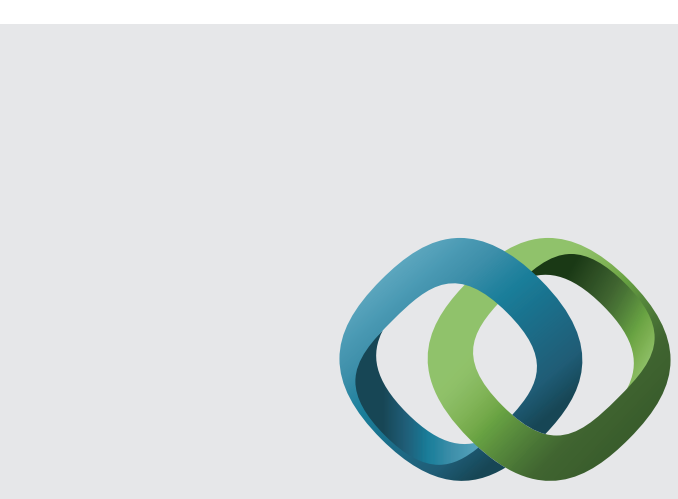

\section{Hindawi}

Submit your manuscripts at

http://www.hindawi.com
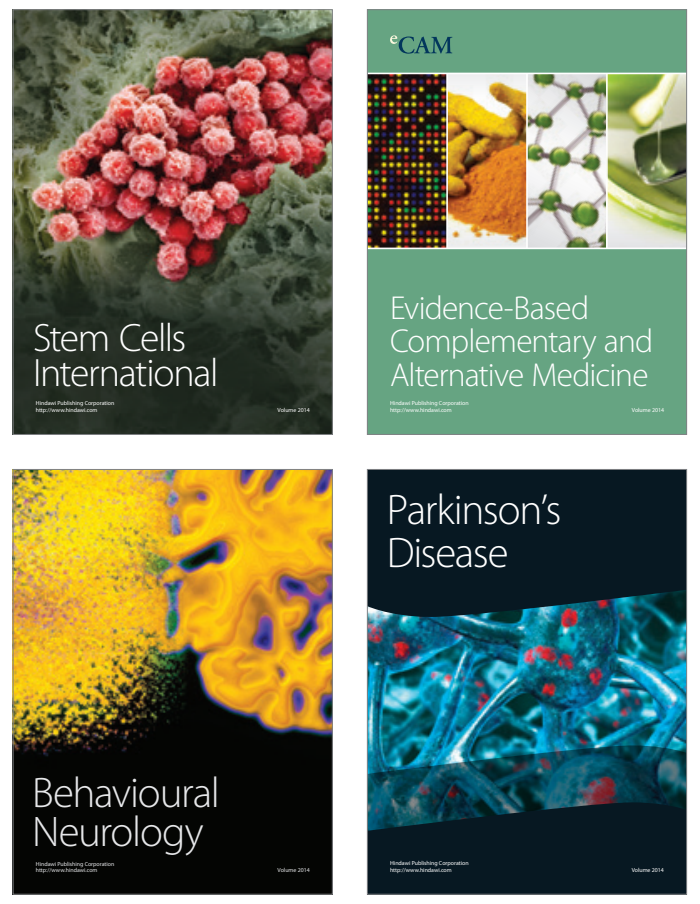
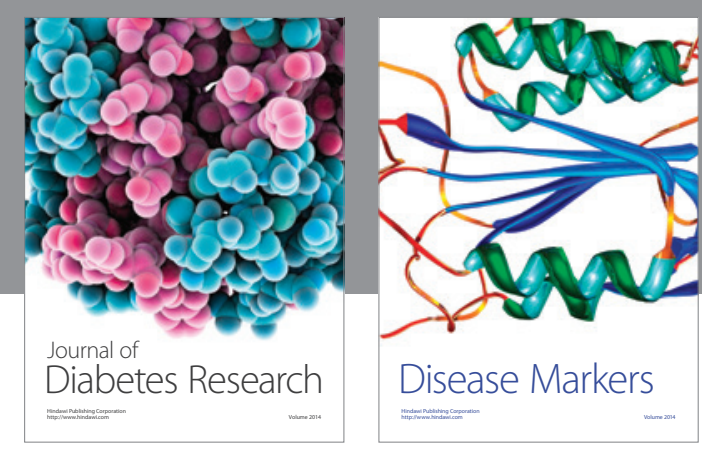

Disease Markers
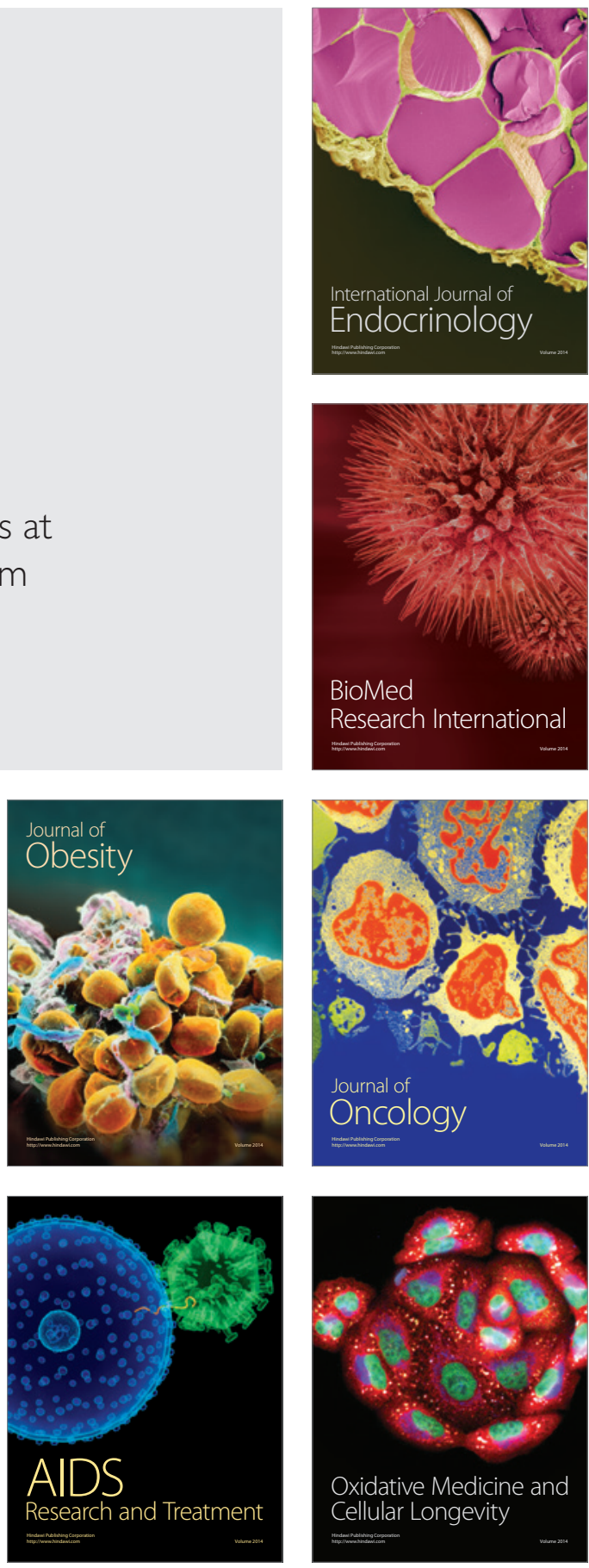